\author{
NANAEKE \\ Indonesian Journal of Early Childhood Education \\ Volume 3, Nomor 1, Juni 2020
}

\title{
PENGARUH PERMAINAN ULAR TANGGA ISLAMI TERHADAP PERILAKU MORAL ANAK PADA KELOMPOK B TK CITRA SAMATA
}

\author{
Andi Sitti Hartika \\ Jurusan Pendidikan Islam Anak Usia Dini \\ Fakultas Tarbiyah dan Keguruan, UIN Alauddin Makassar \\ E-mail: andisittihartika@gmail.com \\ Ahmad Afiif \\ Jurusan Pendidikan Islam Anak Usia Dini \\ Fakultas Tarbiyah dan Keguruan, UIN Alauddin Makassar \\ e-mail:ahmad.afiif@uin-alauddin.ac.id \\ Besse Marjani Alwi \\ Jurusan Pendidikan Islam Anak Usia Dini \\ Fakultas Tarbiyah dan Keguruan, UIN Alauddin Makassar \\ e-mail:marjanialwi@gmail.com
}

\begin{abstract}
Abstrak
Penelitian ini bertujuan: (1) untuk mengetahui gambaran perilaku moral anak sebelum melakukan permainan ular tangga Islami pada kelompok B TK Citra Samata, (2) untuk mengetahui gambaran perilaku moral anak setelah melakukan permainan ular tangga Islami pada kelompok B TK Citra Samata, (3) untuk mengetahui apakah ada pengaruh permainan ular tangga Islami terhadap perilaku moral anak pada kelompok B TK Citra Samata. Penelitian ini adalah penelitian kuantitatif dengan jenis penelitian quasi eksperimendengan desain penelitian one group pretest posttes design. Populasi dalam penelitian adalah seluruh anak pada TK Citra Samata yang berjumlah 24 orang yang terbagi ke dalam 4 kelas (kelas A, B1, B2, dan B3). Jumlah sampel adalah sebanyak 24 orang. Teknik pengambilan sampel dengan Sampling Jenuh, dimana semua jumlah populasi dijadikan sampel. Instrumen yang digunakan dalam penelitian ini adalah lembar observasi. Teknik analisis yang digunakan adalah analisis statistik deskriptif dan analisis statistik inferensial. Hasil penelitian menunjukkan bahwa; (1) Perilaku moral anak sebelum melakukan permainan ular tanggga Islami pada kelompok B TK Citra Samata berada pada kategori Sedang dengan rentang nilai 16-29 dengan nilai rata-rata 18. (2) Perilaku moral anak setelah melakukan permainan ular tangga Islami pada kelompok B TK Citra Samata berada pada kategori Tinggi dengan rentang nilai 34-37 dengan nilai rata-rata 35. (3) Hasil penelitian jika dibandingkan sebelum dan setelah melakukan permainan ular tangga Islami maka terdapat pengaruh positif terhadap perilaku moral anak pada kelompok B TK Citra Samata.
\end{abstract}

Kata Kunci: Permainan Ular Tangga, Perilaku Moral Anak Usia Dini 


\begin{abstract}
The aim of this study (1) to know the description of the moral behavior of children before playing the Islamic ladder snake game in group B Citra Samata Kindergarten, (2) to find out the description of children's moral behavior after playing the Islamic snake ladder game in group B Citra Samata Kindergarten, ( 3) to find out whether there is an influence of the Islamic snakes and ladders game on the moral behavior of children in group B Citra Samata Kindergarten. This research is a quantitative research with quasi experimental design with pretest and posttest groupdesign. The population of this study were all 24 children in Samata Kindergarten who divided into 4 classes (class A, B1, B2, and B3). The total samplingwere involved with 24 children.The instrument used in this study was the observation sheet. The analysis technique used was descriptive statistical analysis and inferential statistical analysis. The results showed that; (1) Moral behavior of children before playing the Islamic snake game in group B Citra Samata Kindergarten was in the Medium category with a range of grades 16-29 with an average value of 18. (2) Moral behavior of children after playing the Islamic snakes and ladder game in group B Citra Samata Kindergartens in the High category with a range of 34-37 with an average value of 35. (3) The results of the study before and after playing the Islamic ladder game required a positive influence on children's moral behavior in group B Citra Samata Kindergarten.
\end{abstract}

Kata Kunci: Snakes and Ladders Game, Moral behavior of Children

\title{
PENDAHULUAN
}

Anak adalah salah satu anugerah paling berharga dari Allah swt. Sebagai titipan dan amanah. Orangtuanya memiliki kewajiban untuk menjaga, merawat, dan mendidik, serta mengarahkannya agar dapat berkembang secara optimal, sesuai dengan potensi yang dimilikinya (Wibowo, 2017). Salah satu cara untuk mengembangkan potensi anak adalah melalui pendidikan anak sejak usia dini.

Pendidikan Anak Usia Dini menurut Undang-Undang Sistem Pendidikan Nasional No. 20 tahun 2003 adalah suatu proses yang diberikan kepada anak sejak lahir sampai berusia enam tahun yang dilakukan dengan memberikan sebuah rangsangan pendidikan untuk membantu pertumbuhan danperkembangan jasmani dan rohani supaya anak memiliki kesiapan dalam memasuki pendidikan lebih lanjut. Pendidikan yang dimulai sejak dini lebih merangsang otak anak untuk mendapatkan pendidikan-pendidikan selanjutnya (Latif, 2013).

Pendidikan anak usia dini sangat penting untuk diberikan kepada anak karena pendidikan merupakan salah satu tahap penting dalam menentukan keberhasilananak dan juga paling mendasar disepanjang rentang pertumbuhan dan perkembangan yang tidak boleh diabaikan (Wibowo, 2017). Oleh karena itu, anak memerlukan pendidikan sejak dini agar mudah mengembangkan seluruh potensiyang terkait dengan perkembangan anak. Salah satu aspek perkembangan anak yang urgen untuk dikembangkan adalah aspek moral. 
Santrock menjelaskan bahwa perkembangan moral adalah perkembangan membahas tentang aturan mengenai apa yang harus dilakukan oleh manusia saat berinteraksi dan berkomunikasi dengan orang lain. Anak ketika dilahirkan belum mewujudkan aspek moralnya, akan tetapi pada diri anak tersebut mempunyai potensi moral yang siap untuk dikembangkan (Nuaraidah, 2017). Aspek moral anak merupakan sesuatu yang dapat berkembang (Gunarsa dan Gunarsa, 2008) . Secara bertahap dia akan mempelajari nilai moral dari lingkungan keluarga yaitu orangtua, kemudian lingkungan sekolah yaitu guru-guru dan juga teman-teman bermain (Susanto, 2012). Stimulasi pendidikan yang bernilai moral sejak usia dini ini diharapkan pada perkembangan selanjutnya anak akan mampu membedakan baik buruk suatu perbuatan, sehingga anak mampu menerapkan dalam kehidupan sehari-hari (Fahliha, 2017)., agarmerekaterhindar dari kenakalan, kriminalitas dan juga mampu menghindari narkoba ketika remaja (Ibung, 2009).

Pam Schiller dan Tamera Bryant mengungkapkan bahwa jiika meninggalkan pelajaran mengenai nilai moral maka suatu negara akan beresiko kehilangan sebagian kedamaian dari budaya. Masa anak usia dini merupakan waktu yang tepat dalam menentukkan begitu pentingnya perilaku moral kepada anak atau bagi masa depannya agar kehidupan anak dapat dijalani dengan baik (Khaironi, 2017). Masa usia dini merupakan masa yang baik untuk perkembangan moral kepada anak, dengan memberitahukan kepada anak tentang bagaimana cara menjadi manusia yang baik, yaitu dengan memberi pemahaman tentang perilaku baik yang harus dilaksanakan dan tentang perilaku buruk yang harus dihindari.

Perilaku moral tidak terjadi begitu saja tanpa adanya proses pembentukan perilaku yang akan menerjemahkan pemahaman nilai moral ke dalam tindakan (Kosasih dan Rahmaniah, 2013). Pembentukan perilaku ini berfungsi untuk mencapai beberapa hal, yaitu menanamkan pembiasaan sikap dan perilaku yang didasari oleh nilai moral sehingga dalam kehidupan anak sesuai dengan nilai-nilai yang telah dijunjung tinggi oleh masyarakat, menjadikan anak yang matang dan mandiri, menanamkan pribadi yang baik, membantu anak untuk membedakan perilaku yang baik dan buruk, dan menjadi pribadi yang anggun. Selain itu, agar anak juga berusaha menyadari untuk menghindari perilaku yang tercela (Suryana, 2016).

Menurut Ahmad Nawawi, pendidikan moral kepada anak sangat penting karena anak merupakan generasi penerus bangsa, agar kualitas hidup semakin meningkat (Khaironi, 2017). Dengan pendidikan moral kepada anak, diharapkan seiring pertumbuhan dan perkembangan, anak dapat berperilaku dalam kehidupan sehari-harinya sesuai dengan nilai-nilai moral yang telah dijunjung tinggi oleh masyarakat berdasarkan hukum-hukum Islam. (Agustiningsih, 2005). Namun demikian, fakta di TK Citra Samata pada kelompok B usia 5-6 tahun berdasarkan hasil observasi pendahuluan pada tanggal 29 Juli 2019, menunjukkan bahwa perkembangan moral anak belum berkembang dengan optimal. Terdapat beberapa 
anak yang berbicara kasar kepada temannya, bahkan masih ada beberapa anak makan dan minum sambil berjalan. Hasil wawancara dengan salah seorang wali kelas di sekolah tersebut menunjukkan perkembangan perilaku moral anak belum berkembang dengan baik, ditandai banyaknya anak tidak mengucapkan salam ketika masuk dan keluar kelas, anak jarang mengajak salaman gurunya ketika datang dan menjelang pulang sekolah, anak juga sering tidak mengucapkanterima kasih ketika mendapatkan sesuatu, beberapa anak juga tidak menunjukkan sikap tanggung jawab seperti tidak mengembalikan mainan yang sudah digunakan ke tempat semula, serta tidak sabar menunggu giliran.

Beberapa pakar mengatakan, untuk mengembangkan perilaku moral anak usia dini adalah melalui aktivitas bermain. Menurut Wiyana, bermain bagi anak usia dini sudah tidak asing lagi, karena bermain merupakan kebutuhan anak. Beberapa pakar Pendidikan Anak Usia Dini (PAUD) mengatakan bahwa dunia anak adalah dunia bermain, karena bermain merupakan aktivitas yang menyenangkan bagi anak usia dini. Anak menghabiskan sebagian besar waktunya hanya untuk bermain, bahkan beberapa ahli psikologi perkembangan anak sering mengatakan bahwa anak belajar sambil bermain atau bermain sambil belajar (Purnama, 2019). Untuk mengembangkan dan membentuk perilaku moral anak, maka guru dapat melakukannya melalui permainan. Salah satu bentuk permainan yang dapat dilakukan adalah dengan menerapkan permainan ular tangga Islami pada anak.

Permainan ular tangga Islami adalah aktivitas yang menyenangkan yang dimainkan oleh dua anak atau lebih dengan menggunakan media spanduk dan kartu. Permainan ular tangga terdapat kotak-kotak besar serta gambar tangga dan ular yang di dalamnya mengandung konsep materi nilai-nilai moral yang akan menstimulasi perilaku moral anak. Ular tangga Islami adalah permainan yang mudah dilakukan oleh anak-anak, sehingga dapat menciptakan suasana pembelajaran yang menyenangkan.

Berdasarkan latar belakang di atas maka rumusan masalah dalam penelitian ini adalah adakah pengaruh permainan ular tangga Islami terhadap perilaku moral anak pada kelompok B TK Citra Samata. Adapun tujuan penilitian ini adalah untuk mengetahui pengaruh permainan ular tangga Islami perilaku moral anak pada kelompok B TK Citra Samata. Adapun hipotesis penelitin adalah terdapat pengaruh permainan ular tangga Islami terhadap perilaku moral anak pada kelompok B TK Citra Samata

\section{METODE PENELITIAN}

Penelitian ini adalah penelitian kuantitatif dengan jenis penelitian quasi eksperimen dengan desain pone group pretest posttes design. Populasi dalam penelitian ini adalah seluruh anak pada TK Citra Samata yang berjumlah 24 orang yang terbagi ke dalam 4 kelas (kelas A, B1, B2, dan B3). Jumlah sampel adalah sebanyak 24 orang. Teknik pengambilan sampel dengan Sampling Jenuh, dimana 
semua jumlah populasi dijadikan sampel. Instrumen yang digunakan dalam penelitian ini adalah lembar observasi. Teknik analisis yang digunakan adalah analisis statistik deskriptif dan analisis statistik inferensial.

\section{HASIL DAN PEMBAHASAN}

Berdasarkan hasil penelitian yang dilakukan, diperoleh bahwa Perilaku moral anak di TK Citra Samata pada kelas eksperimen yakni Pre-test diperoleh bahwa, berada pada kategori Sangat Tinggi sebanyak 1 orang dengan rentang nilai 24-27 atau 4,16\%, kategori Tinggisebanyak 7 orang atau $29,16 \%$ dengan rentang nilai 20-23, kategori Sedangsebanyak 13 orang dengan rentang nilai 16-19 atau $54,16 \%$, kategori Rendahsebanyak 3 orang dengan rentang nilai 12-15 atau $12,5 \%$. Hasil tersebut menggambarkan bahwa perilaku moral anak pretest (kelas eksperimen) terhadap perilaku moral anak berada pada kategori Sedangkarena jumlah persentasenya sebesar 54,16\% dengan rentang nilai 16-19.

Hasil Post-test diperoleh bahwa, 7 orang berada pada kategori Sangat Tinggidengan rentang nilai 37-39 atau 29,16\%, kategori Tinggisebanyak 11 orang atau 45,83 \% dengan rentang nilai 34-36, kategoriSedangsebanyak 3 orang atau $12,5 \%$ dengan rentang nilai 31-33, kategoriRendah sebanyak 3 orang atau 12,5\% dengan rentang nilai 28-30. Berdasarkan data diatas menunjukkan bahwa perilaku moral anak posttest (kelas eksperimen) terhadap permainan ular tangga Islami pada kelompok B TK Citra Samata berada pada kategori Tinggi dan signifikan karena jumlah persentasenya 45,83 \% dengan rentang nilai 34-36.

Hasil analisis pada pegujian statistic inferensial yaitu uji t, diperoleh hasil uji hipotesis $t_{\text {nitung }}\left(t_{0}\right)=12,06>$ dari $t_{\text {tabel }}$ yakni 2,07. Karena $t_{\text {hitung }}<t_{\text {tabel }}(12,06>$ $2,07) \mathrm{Jadi}, \mathrm{H}_{0}$ di tolak dan $\mathrm{Ha}$ di terima, artinya terdapat pengaruh permainan ular tangga Islami terhadap perilaku moral anak pada kelompok B TK Citra Samata.

Hasil penelitian ini menunjukkan bahwa permainan ular tangga Islami dapat mengembangkan perilaku moral anak pada kelompok B TK Citra Samata. Permainan ular tangga Islami yang dilakukan juga sangat mampu menciptakan suasana belajar menjadi kreatif dan menyenangkan.

Ular tangga Islami mampu membuat perilaku moral anak menjadi lebih baik, karena permainan ular tangga Islami mengandung nilai-nilai moral yang akan memberikan pemahaman kepada anak-anak mengenai perilaku yang baik atau yang yang tidak baik. Beberapa nilai moral atau indikator pencapaian perkembangan moral anak yang diambil sesuai dengan permasalahan yang ada pada TK tersebut, yaitu:

Ular tangga Islami mampu membuat perilaku moral anak menjadi lebih baik, karena permainan ular tangga Islami mengandung nilai-nilai moral yang akan memberikan pemahaman kepada anak-anak mengenai perilaku yang baik atau yang tidak baik.

Beberapa nilai atau indikator pencapaian perkembangan moral anak yang 
diambil sesuai dengan permasalahan yang ada pada sekolah tersebut, yaitu bersikap sopan, hormat, menjaga kebersihan diri dan menjaga kebersihan lingkungan

Indikator sopan, terbagi empat perilaku yang diukur antara lain:

Pertama, anak mampu berbahasa sopan dan santun: salah satu nilai moral anak dalam permainan ular tangga Islami ini yaitu anak mampu berbahasa sopan dan santun. Permainan ini anak mampu memahami perilaku baik yang harus dilaksanakan dan perilaku buruk yang harus dihindari.

Berdasarkan pada kotak 16 yang kartunya bertulis "anak yang suka berbicara sopan santun mendapatkan kesempatan menaiki tangga", jadi ketika anak berhenti pada kotak 16, anak akan paham bahwa ketika anak berbicara sopan santun merupakan perbuatan yang baik, sehingga pada kotak tersebut memberi kesempatan untuk menaiki tangga. Oleh karena itu, permainan ini salah satu cara untuk mengembangkan perilaku moral anak. Salah satunya yaitu sifat sopan dan santun, dalam ajaran Islam sangat dianjurkan untuk memiliki sifat sopan dan santun,I. Hal tersebut telah dijelaskan dalam al-Qur'an dan Hadits Nabi bahwa santun merupakan salah satu keindahan jiwa dan akhlak tertinggi yang menjadikan manusia berada pada kesempurnaan budi pekerti. Diriwayatkan dari Aisyah ra, Rasululah saw bersabda, yang artinya "Sesungguhnya Allah Maha Lemah Lembut yang mencintai kelembutan. Dan Allah memberikan pada kelemahlembutan yang tidak Dia berikan pada kekerasan, dan tidak pula Dia berikan pada selainnya." (HR.Muslim) (Abdullah, 2013).

Kedua, mengucapkan terima kasih ketika mendapatkan sesuatu: salah satu nilai moral anak dalam permainan ular tangga Islami ini yaitu "mengucapkan terima kasih ketika mendapatkan sesuatu", Salah satu pembiasaan yang harus ditanamankan kepada anak yaitu membiasakan anak mengucapkan "terima kasih" ketika mendapatkan sesuatu, selaras yang dikatakan oleh Rinda dalam penelitian Afifah, dkk, bahwa orang tua atau seorang pendidik harus mengingatkan anak untuk selalu mengucapkan "teima kasih" ketika diberi atau mendapatkan kebaikan dari orang lain (Nurftri dkk, 2020). Nilai moral ini dalam penelitian ini, terdapat pada kotak 7 , ketika anak berhenti berjalan pada kotak tersebut, maka anak diberikan pemahaman tentang pentingnya "ucapan terima kasih" saat mendapatkan kebaikan.

Ketiga, makan dalam keadaan duduk: salah satu nilai moral anak dalam permainan ular tangga Islami ini yaitu makan dalam keadaan duduk. Pada permainan ini, pada kotak 19 yang kartunya bertulis "anak yang suka makan sambil berjalan, harus turun mengikuti ular", apabila anak berhenti berjalan pada kotak tersebut, anak akan paham bahwa makan sambil berjalan adalah termasuk perilaku yang buruk, karena pada kotak tersebut anak diharuskan turun mengikuti ular, sehingga dalam kehidupan sehari-hari anak akan berusaha untuk tidak 
melakukan perbuatan tersebut, sehingga dengan permainan ini perilaku moral anak akan lebih baik dari sebelumnya.

Keempat, minum dalam keadaan duduk: permainan ular tangga Islami ini terdapat nilai moral anak yaitu "minum dalam keadaan duduk", nilai moral ini terdapat pada kotak 17. Ketika anak berhenti berjalan pada kotak tersebut, guru memberikan pemahaman mengenai pentingnya minum dalam keadaan duduk, dan anak diminta untuk mempraktekkannya. Pada permainan ini memberikan pembelajaran yang baik kepada anak, bertujuan agar anak terbiasa minum dalam keadaan duduk. Kebiasaan ini akan menjadi karakter, karakter ini sudah dianjurkan dalam ajaran Islam sesuai dengan petunjuk Nabi saw. dalam masalah minum, tidaklah minum sambil berdiri. Diriwayatkan oleh Muslim dari hadits Abu Hurairah ra. la berkata bahwa Nabi saw. Bersabda yang artinya “janganlah salah seorang diantara kalian itu minum dengan berdiri. Barangsiapa yang lupa maka hendaklah dia memuntahkannya" (Abdullah, 2013).

Indikator hormat, terbagi beberapa perilaku yang diukur antara lain:

Satu, mengucapkan salam sebelum masuk kelas dan keluar kelas: pada permainan ular tangga Islami ini terdapat pembelajaran nilai moral yaitu "mengucapkan salam sebelum masuk kelas" terdapat pada kotak 3 dan "mengucapkan salam sebelum keluar kelas" terdapat pada kotak 4. pada permainan ini, ketika anak berhenti berjalan pada kotak tersebut, anak akan mempraktekkan nilai moral tersebut sesuai yang tertulis pada kartu tersebut dalam kotak itu, sehingga anak akan mampu membiasakan diri mengucapkan salam sebelum masuk dan keluar kelas. Oleh karenanya itu dengan permainan ini perilaku moral anak lebih berkembang dari sebelum anak melakukan permainan ular tangga Islami ini.

Kedua, menyalami tangan guru sebelum masuk kelas dan keluar kelas: nilai moral yang ada dalam permainan ular tangga Islami ini yaitu "menyalami tangan guru sebelum masuk kelas" terdapat pada kotak 9 dan "menyalami tangan guru sebelum keluar kelas" terdapat pada kotak 14. Permainan ini, anak diminta untuk mempraktekkan nilai moral tersebut apabila dia berhenti berjalan pada kotak itu, sehingga anak juga membiasakan melakukan hal tersebut setelah melakukan permainan ular tangga Islami dalam kehidupannya baik di sekolah maupun di luar sekolah. Menyalami tangan guru sebelum masuk kelas dan keluar kelas adalah suatu bentuk kehormatan kepada guru. Dalam buku tentang "Pendidikan Anak dalam Islam" menjelaskan bahwa hendaknya seorang murid harus mengetahui kewajibannya terhadap gurunya yaitu hendaknya seorang murid ketika melihat gurunya harus dengan sikap hormat dan tahu bahwa kedudukan seorang guru lebih tinggi kedudukannya, sehingga dengan sikap tersebut akan lebih mudah untuk mengambil manfaat dari gurunya Abdullah, 2013).

Ketiga, sabar menunggu giliran: salah satu nilai moral anak dalam permainan 
ular tangga Islami ini yaitu "sabar menunggu giliran". Jadi berdasarkan pada kotak 11 yang kartunya bertulis "anak yang sabar dalam menunggu giliran mendapatkan kesempatan menaiki tangga”, jadi ketika anak berhenti pada kotak 11, anak akan paham bahwa ketika anak sabar dalam menggu giliran merupakan perbuatan yang baik, karena pada kotak tersebut mendapatkan kesempatan untuk menaiki tangga. Oleh karenanya itu dengan permainan ular tangga Islami ini mampu memberikan pengaruh baik terhadap perilaku moral pada anak.

Indikator menjaga kebersihan, terbagi beberapa perilaku yang diukur, antara lain:

Satu, menjaga kebersihan diri, yaitu mencuci tangan sebelum makan dan setelah makan: permainan ular tangga Islami ini, anak akan mampu membedakan tentang perilaku baik dan buruk, karena permainan ini ada contoh perilaku baik yang mendapatkan kesempatan menaiki tangga dan ada contoh perilaku buruk yang harus turun mengikuti ular. Salah satunya dapat dilihat yaitu pada kotak 12 yaitu tentang perilaku buruk "anak yang tidak mencuci tangan sebelum makan dan setelah makan, harus turun mengikuti ular", jadi ketika anak berhenti berjalan pada kotak tersebut, maka anak akan turun mengikuti ular, sehingga anak akan paham ketika tidak mencuci tangan sebelum makan dan setelah makan adalah suatu perilaku tidak baik. Mencuci tangan sebelum makan dan setelah makan termasuk Perilaku Hidup Bersih dan Sehat (PHBS). Perilaku Hidup Bersih dan Sehat merupakan bagian dari kemampuan dasar nilai agama dan moral. Perilaku tersebut diharapkan agar dapat diterapkan ketika anak masih dalam usia dini, melalui pemberian contoh yang baik sehingga menjadi kebiasaan dalam kehidupan sehari-harinya (Julianti dkk, 2017).

Kedua, menjaga kebersihan lingkungan, yaitu merapikan mainan setelah bermain: merapikan mainan setelah bermain termasuk menjaga kebersihan lingkungan. Menjaga kebersihan lingkungan termasuk perilaku moral. Perilaku moral ini terdapat pada kotak 2 yaitu "anak yang suka merapikan mainan setelah bermain mendapatkan kesempatan menaiki tangga", jadi ketika anak berhenti berjalan pada kotak tersebut, anak akan mendapatkan kesempatan menaiki tangga, dan anak akan paham bahwa merapikan mainan setelah bermain termasuk perilaku yang baik.

\section{SIMPULAN}

Berdasarkan hasil penelitian dan pembahasan pada penelitian ini, maka diperolehkesimpulanbahwa perilaku moral anak sebelum melakukan permainan ular tangga Islami pada kelompok B TK Citra Samataperluuntukdikembangkanlagi. Namun setelah melakukan permainan ular tangga Islami, perilaku moral anak pada kelompok B TK Citra Samata telah terdapat peningkatan. Jadi,permainan ular tangga Islami telah memberikan pengaruh positif untuk mengembangkan perilaku moral anak pada kelompok B TK Citra Samata. 


\section{DAFTAR PUSTAKA}

Abdullah. (2013). Pendidikan Anak dalam Islam. Solo: Insan Kamil.

Agustiningsih, R. (2019). Pembinaan Moral Anak di Panti Pamardi Putra Mandiri Sendangguwo Kecamatan Tembalang Kota Semarang. Skripsi. Semarang: Universitas Negeri Semarang.

Fiahliha, A. (2017) Implementasi Pengembangan Nilai Agama Moral pada Anak Usia Dini Melalui Metode Keteladanan di Tk Aisyiyah 1 Sawahan Ngemplak Boyolali. Skripsi. Surakarta: IAIN Surakarta.

Gunarsa, D.S dan Gunarsa, Y.S. (2019). Psikologi Perkembangan. Jakarta: PT BPK Gunung Mulia.

Ibung, D. (2009). Mengembangkan Nilai Moral pada Anak. Jakarta: PT Elex Media.

Julianti, R., Nasirun, H.M. dan Wembrayanti. (2017). Perilaku Hidup Bersih dan Sehat (PHBS) di Lingkungan Sekolah. Jurnal IImiah Potensia, 3 (1), 11-17.

Khaironi, M. (2017). Pendidikan Moral pada Anak Usia Dini. Jurnal Golden Age, 1 (1), 1-16.

Kosasih dan Rahamania, F. (2013). Perilaku Moral Anak Usia 4-5 Tahun di Taman Kanak-Kanak, JISI, 1 (1), 1-8.

Latif, M., Zulkharina, Zubaidah, R. dan Adanda, M. (2013). Orientasi Baru Pendidikan Anak Usia Dini: Teori dan Aplikasi. Jakarta: Kencana.

Nuraidah, A. (2017) Pengaruh Film Animasi Adit dan Sopo Jarwo Terhadap Perkembangan Moral Anak usia Dini. Skripsi. FKIP Universitas Muhammadiyah Purwokerto.

Fitri, A.N., Jubaaedah, Y. dan Ningsih, M.P. (2016). Peran Orang Tua dalam Penanaman Disiplin pada Anak Usia Prasekolah melalui Pembiasaan di Kelurahan Cihaurgeulis Bandung. Jurnal FamilyEdu, II (2). 81-91.

Purnama, S. (2019). Pengembangan Alat Permainan Edukatif Anak Usia Dini. Bandung: PT Remaja Rosdakarya.

Suryana, D. (2016). Pendidikan Anak Usia Dini: Stimulasi dan Aspek Perkembangan Anak. Jakarta: Kencana.

26 NANAEKE - Indonesian Journal of Early Childhood Education, Vol. 3, No. 1, Juni 2020 
Susanto, A. (2012) Perkembangan Anak Usia Dini: Pengantar dalam Berbagai Aspeknya. Jakarta: Prenadamedia Group.

Wibowo, A. (2017). Pendidikan Karakter Usia Dini (Strategi Membangun Karakter di Usia Emas). Yogyakarta: Pustaka Pelajar. 